\title{
New insights into the signaling and function of cytokinins in higher plants
}

\author{
Agnieszka Ciesielska, Milosz Ruszkowski, Alina Kasperska, \\ IWONA FemiaK, ZBigniew Michalski, Michą M. SiKorSKi * \\ Institute of Bioorganic Chemistry, Polish Academy of Sciences, Poznań, Poland \\ *Corresponding author: mmsik@ibch.poznan.pl
}

\begin{abstract}
Phytohormones (plant hormones) play a role in the regulation of cellular activities including cell division, elongation and differentiation, pattern formation, organogenesis, reproduction, sex determination, and responses to abiotic and biotic stress. The phytohormonal signal transduction pathways operate via cytokinin perception by transmembrane receptors consisting of two domains: an extracellular domain responsible for hormone binding and an intracellular domain, sensory His / Asp kinase (HK). Upon phytohormone binding, the receptor undergoes a conformational change which activates its protein kinase activity. The phosphorylated intracellular domain transfers the phosphoryl group to the His residue of the histidine phosphotransfer protein (HPt) which in turn phosphorylates Asp residue in the Response Regulator (RR). The phosphorylated RR protein acts as either a positive or negative transcription factor that interacts with the gene promoter or other target protein. The two-component signaling pathway, operating through the His-Asp phosphorelay, controls many physiological and developmental processes throughout the plant lifecycle (from seed-to-seed). Downstream plant hormone signaling also includes proteolysis of transcriptional regulators that block the activity of transcription factors. Two-component signaling operates more frequently in higher plants. Five classic plant hormones had been discovered by the middle of the twentieth century: auxins, cytokinins, gibberellins, ethylene and abscisic acid. The more recently characterized hormones include brassinosteroids, strigolactones, jasmonates and salicylates. Considering the tremendous work that has been undertaken during the last decades, in this review we decided to concentrate on cytokinin signaling in various plant developmental processes, including responses to biotic and abiotic stresses.
\end{abstract}

Key words: signal transduction, cytokinin, phytohormone, cytokinin receptor, histidine-aspartate phosphorelay, two-component relay system, legume plants, symbiosis

\section{Introduction}

Plant hormones (phytohormomes) are small chemical molecules that play a crucial role in plant growth, differentiation and development. They are classified into 9 groups, based on their chemical structure and function in various physiological processes (Table 1).

Cytokinins, a group of cell chemical mediators, play an important role in the regulation of physiological, metabolic, developmental and biochemical processes during plant ontogenesis. Cytokinin action, like that of other phytohormones, is mainly pleiotropic. Its impact depends on the concentration ratio of different plant hormones, as well as the balance and cross-talk between them (Pieterse et al., 2009; Wang and Irving, 2011).

Naturally occurring cytokinins are adenine derivatives. However, synthetic cytokinins, i.e. urea derivati- ves, show a higher activity in in vitro cultures than natural phytohormones (Fig. 1). Natural derivatives of adenine (trans-zeatin, 2iP, etc., Table 1) are stored or transported as ribosides via membrane channels and finally hydrolyzed to free physiologically active hormones and ribose. They are then recognized by the membrane receptor with an intracellular histidine kinase activity. Hormone recognition is the first step of the signal transduction pathway.

\section{Synthesis and degradation of cytokinins}

Cytokinin homeostasis is partially and temporarily regulated though the balance between its synthesis and degradation processes. Cytokinins (such as $2 \mathrm{iP}$ riboside and zeatin riboside) occur in a bound form in the anticodons of tRNA specific for serine, isoleucine, tyrosine 
Table 1. Classification of phytohormones

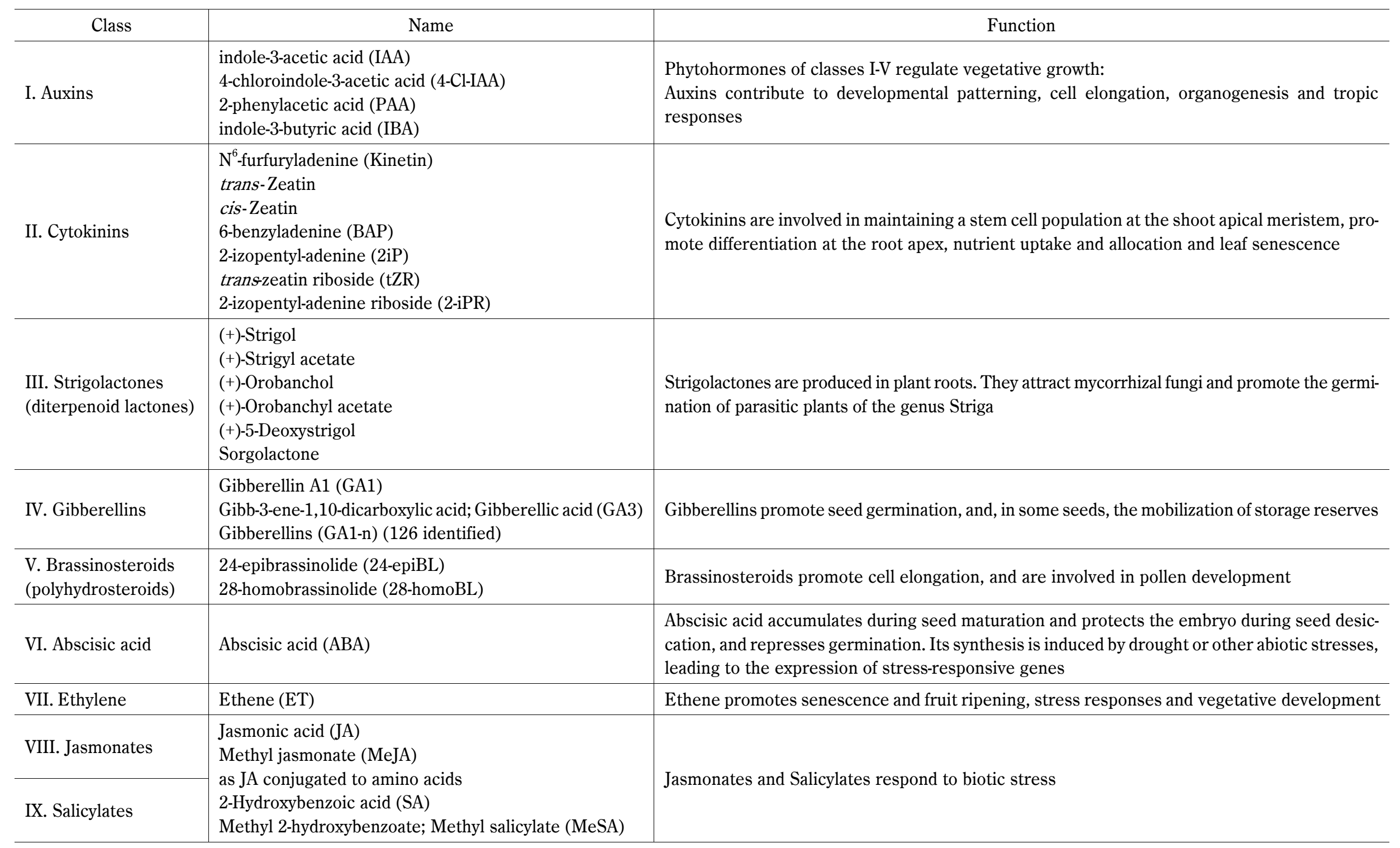

(Acc. to: http://dx.doi.org/10.1105/tpc.110.tt0310) 


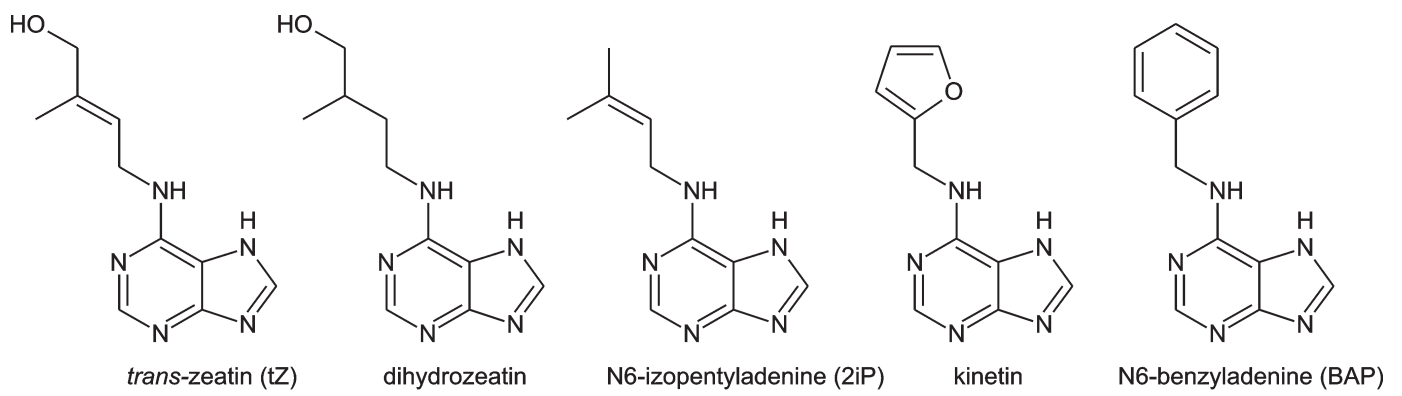

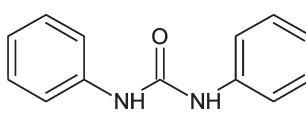

N,N'-diphenylurea (DPU)

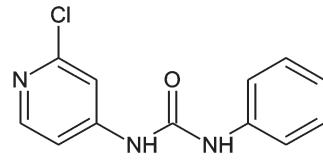

N-(2-chloro-4-pirydyl)N9-phenylurea (4-CPPU)

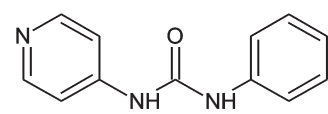

N-phenylN9-(4-pirydyl)urea (4-PU)

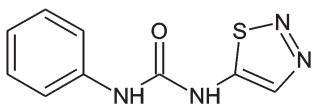

thidiazuron (TDZ)

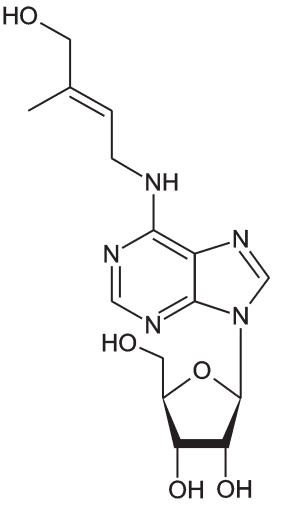
trans-zeatin
riboside (tZR)<smiles>CC(C)=CCN</smiles>

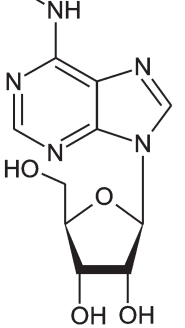

N6-izopentyladenine riboside (2iPR)

Fig. 1. Structures of natural and synthetic cytokinins and their ribosides. Five adenine-derivatives, four urea-derivatives and two cytokinin ribosides are shown

and cysteine (Armstrong et al., 1969; Barciszewska et al., 1988; Skoog et al., 1966), in rRNA (Murai et al., 1978) and in the vicinity of the mRNA poliadenylate region (e.g. BA riboside) (de la Serve et al., 1984). Currently, two independent pathways of spare cytokinin synthesis are postulated: either by (i) the release of cytokinin during oxidatative degradation of nucleic acids (RNA and DNA) or ii) de novo synthesis (Schmulling, 2004). Cis-zeatin type cytokinins (cZ-type) are created during the tRNA. tRNA isopentenyltransferases (tRNA IPT) produce cis-hydroxy isopentenyl tRNA which is further degraded to cis-zeatin (Hirose et al., 2008; Miyawaki et al., 2006). Cis-zeatin undergoes conversion into a biologically active form, i.e. trans-zeatin, in a reaction catalyzed by enzymes from the group of cis-/trans -isomerases. The slow turnover rate of tRNA is, however, insufficient to fulfill the cell requirement for cytokinins (Barciszewski et al., 2000; Czerpak and Piotrowska, 2003; Haberer and Kieber, 2002). The key enzyme in the de novo synthesis pathway of cytokinin is adenosine phosphateisopentenyltransferase (IPT). It uses ATP, ADP or AMP as substrates and catalyzes the first reaction. This reaction is a rate-limiting step in cytokinin biosynthesis. The completion of the Arabidopsis thaliana genome enabled
Takei and co-workers (2001) to identify nine genes encoding putative AtIPT genes. An analysis of AtIPT gene expression profiles indicated not only the root meristem as the place of cytokinin synthesis, but also young leaves, flowers, immature seeds, phloem tissue, embryos and the nodal stem. On the basis of this finding it might be suggested that cytokinins are synthesized all over the plant organism. The expression profiles of AtIPT genes, however, exhibit considerable discrimination within the diverse range of plant tissues and organs (Miyawaki et al., 2004; Nordström, 2004). The presence of nitrogen, sulphate and phosphate apparently modulates $I P T$ gene expression (Hirose et al., 2008; Sakakibara, 2006). Cytokinins that appear in plant cells surrender various transformations and modifications, including glycosylation, hydroxylation and ribosilation. As a consequence, inactive cytokinins are produced and they may act as a cytokinin store or a transport pool. Inactive cytokinin forms (e.g. nucleotides, nucleosides) may be reconverted into active ones in the reaction with the phosphoribohydrolase enzyme, encoded by the $L O G$ gene (LONELY GUY). Neither cytokinin ribosides nor glycosides possess physiological activity in planta (Kudo et al., 2010; Kurakawa et al., 2007). Irreversible cytokinin de- 
gradation is strictly regulated by cytokinin oxidases/dehydrogenases (CKXs) (Ashikari et al., 2005). They cleave the N6-side chain by oxidation, which yields a corresponding aldehyde and adenine or adenosine (Frebort et al., 2011). The reaction requires an abundance of molecular oxygen as an electron acceptor. $C K X$ s gene expression profiles differ between one another depending on the plant organs, the physiological state and environmental conditions (Perilli et al., 2010). Cytokinin degradation processes are significant factors in the regulation of their biological activity.

\section{Cytokinin transport}

Cytokinins are mobile plant hormones. As a result, hormone transport mechanisms are involved in the precise induction of cell signaling throughout a plant organism. Radioactively labeled cytokinins applied to leaves were found in other organs, suggesting the existence of some long distance mechanisms of translocation (Foo et al., 2007). Cytokinins synthetized in the root meristem move acropentally (root-to-shoot) through xylem sap by the action of transpiration flow. The major form of cytokinins identified in xylem sap is a transzeatin nucleoside (tZR) (Hirose et al., 2008; Kudo et al., 2010). Root-toshoot transport of CKs is controlled by endogenous and environmental stimuli. Supplementation of nitrate increases the flow rate of root-synthetized cytokinins in maize, followed by accumulation of IPT proteins and response regulator (RR) transcripts in leaves (Takei et al., $2001 ; 2004)$. This finding implies that $t Z R$ acts as a longdistance messenger for nitrate signaling. Bishopp and co-workers (2011) reported that the quantity of cytokinin transported acropentally is low in comparison to basipental (shoot-to-root) transport through phloem (iP-type cytokinins). Cell-to-cell movement of cytokinin requires movement across the plasma membrane in a protoncoupled manner. For cytokinin nucleobases belonging to a large purine permease family (PUP) cellular uptake is mediated by transporters (Nongpiur et al., 2012), while for purine nucleosides mediation is effected by an equilibrative nucleoside transporter family (ENT) (Fig. 2). Cytokinin translocation by PUP is energy dependent and occurs against the concentration gradient. Arabidopsis competition studies have shown that cytokinins use the same transport system as adenine and caffeine. Adenine uptake was competitively inhibited via trans-zeatin (Ce- dzich et al., 2008; Gillissen et al., 2000). The AtPUP1 gene is expressed in all organs except roots. This suggests that in shoots, root-derived free cytokinins are transported out by phloem.

\section{Cytokinin signaling}

The biological function of cytokinins is well described, although the molecular mechanisms of their action has yet to be fully explained. Despite the fact that cytokinins were discovered over 60 years ago (Skoog and Miller, 1957), it was only a decade ago that their receptor (CRE1/AHK4) was identified in Arabidopsis thaliana (Inoue et al., 2001; Suzuki et al., 2001). The gene encoding this histidine kinase is located on chromosome 2 of the Arabidopsis genome. The CRE1 protein is composed of (i) an N-terminal signal domain (CHASE, Cyclases / Histidine kinases Associated Sensory Extracellular), responsible for hormone binding, (ii) an endocellular transmitter domain which possesses kinase activity, (iii) two regulatory domains at the $\mathrm{C}$-terminus. The dissociation constant of the CRE1/trans-zeatin complex, consistent with the natural cytokinin content, remains at $\mu \mathrm{M}$ level (Romanov et al., 2006). The structure of Arabidopsis thaliana AHK4 was solved by Hothorn (2011). It reveals a similarity to the Vigna radiata cytokinin binding protein (CSBP), (Pasternak et al., 2006). Recent studies have demonstrated that CRE1 is located in the ER membrane, which brings new insights to the cytokinin signaling model (Caesar et al., 2011; Wulfetange et al., 2011). It is proposed that cytokinins enter cell cytoplasm using PUP and ENT channels. Subsequently, they are directed to the endoplasmic reticulum and activate cytokinin receptors anchored to the membrane (Heyl et al., 2012; Hothorn et al., 2011; Kudo et al., 2010; Pas et al., 2004). Upon binding the biologically active cytokinin, receptor dimerization and autophosphorylation of conservative His residue occur. The next steps include: (i) translocation of the phosphate group from the histidine residue to the aspartate on the regulatory domain of CRE1, (ii) movement of the phosphate group to the histidine residue of $\mathrm{HPt}$ proteins (histidine phosphotransfer proteins) serving as phosphor carrier proteins. HPt are small (app. $16 \mathrm{kDa}$ ) monomeric proteins linking the initiation of a cytokinin signal in the cell cytoplasm with nuclear gene responses (Tanaka et al., 2004). HPt proteins induce the expression of type-A or type-B response regulators. However, stu- 


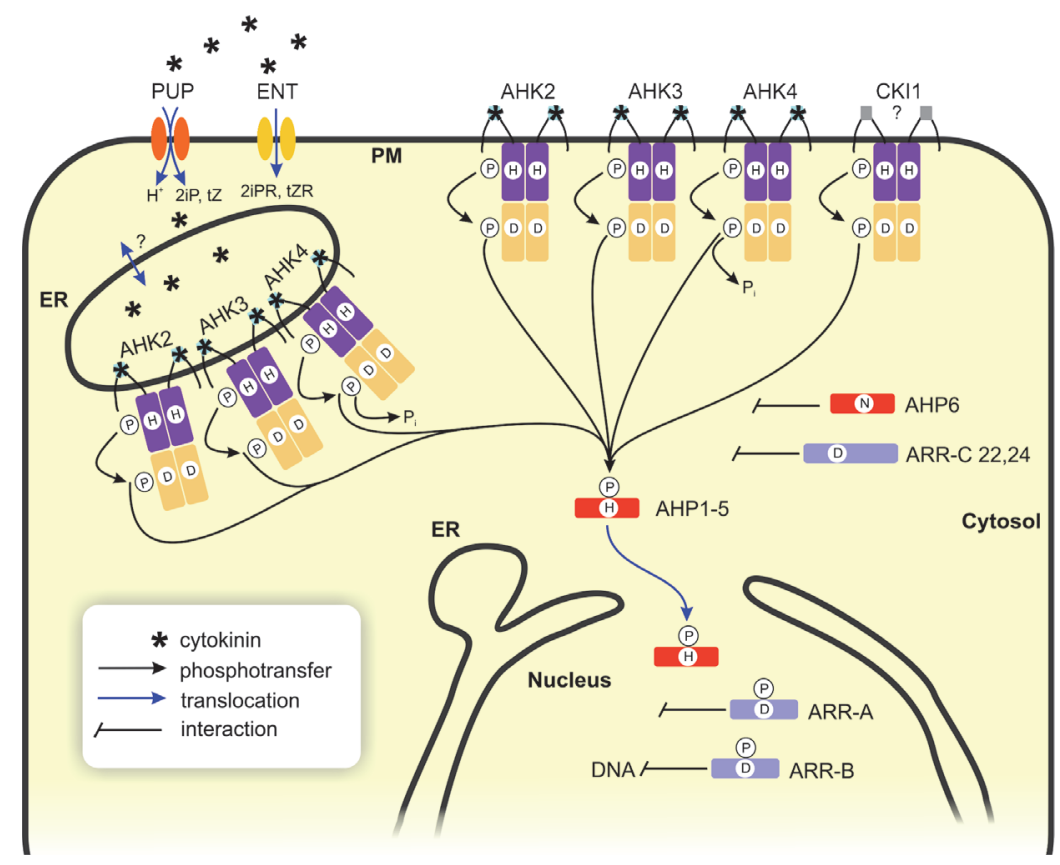

Fig. 2. Cytokinin transduction pathway and active transport. Signaling cascade involves: i) sensory His kinases (AHK2-4) anchored to the plasma membrane (PM) or endoplasmic reticulum (ER); ii) His-containing phosphotransfer protein (AHP1-5) or signal inhibitor (AHP6) and iii) three types of response regulators (ARR-A/B/C). Cytokinin independent kinase (CKI1) is also shown. Active His (H) and Asp (D) residues that transfer phosphate (P) are circled in white. Cytokinins (2iP, tZ) or their ribosides (2iPR, tZR) are transported by two types of channels: purine permeases (PUP) or equilibrative nucleoside transporters (ENT). PUP operates in a proton-coupled manner, while ENT facilitates diffusion of nucleosides according to concentration gradient. Adapted with modifications from (Hwang et al., 2012; Nongpiur et al., 2012)

dies performed by Punwani and co-workers (2010) show that the expression pattern of $h p t$ tgenes is not altered by an exogenously applied cytokinin. It is proposed that HPt proteins contribute to ethylene signaling by interactions with ER-anchored ethylene receptors (ENR) as well (Nongpiur et al., 2012). Response regulators are composed of an N-terminal receiver domain, with the central aspartate residue necessary for acquiring the phosphate group from HPt transmitters. B-type response regulators possess an additional output domain with the ability to bind DNA and activate particular cytokinin sensitive genes (Oka et al., 2002). A-type ARRs create a negative feedback under cytokinin responses, whereas B-type ARRs initiate the expression of cytokinin sensitive genes (Kiba et al., 2003; To et al., 2007).

\section{Cytokinin antagonist}

6-(2-hydroxy-3-methylbenzylamino)-purine, known as PI-55 (Fig. 3), is structurally related to natural cytokinin 6-benzylaminopurine (BAP) with - $\mathrm{OH}$ group at $\mathrm{C} 2$ and $-\mathrm{CH}_{3}$ group at $\mathrm{C} 3$ of the benzyl moiety. PI-55 strongly decreased cytokinin activity and exhibited antagonistic properties to BAP. PI-55 appeared to be a competitive inhibitor of the natural ligand trans-zeatin binding to the Arabidopsis cytokinin receptors (cytokinin response 1, CRE1/AHK4) or Arabidopsis histidine kinase AHK3 (Spichal et al., 2009).

\section{Cytokinins in symbiotic interactions}

Symbiotic interactions between soil bacteria of Rhizobium sp. and a legume plant led to the induction of a root organ: the nitrogen-fixing nodule. Cytokinins appear to be a key differentiation signal of nodule organogenesis by controlling the expression of the NINgene (Nodule Inception) and other transcriptional regulators through mechanisms operating both locally and systemically.

The rhizobial nodulation (Nod) factors identified as lipo-chitooligosaccharide have been revealed to be a crucial bacterial signaling molecule in a symbiotic interaction. They promote root infection and nodule formation (Roche et al., 1991). Nevertheless, the implications of cytokinins in symbiotic interactions have been clearly 


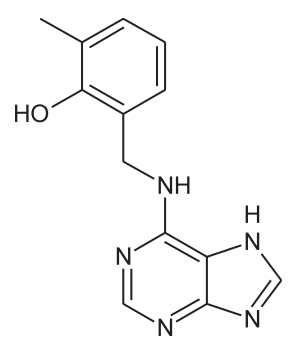

Fig. 3. Structure of cytokinin antagonist PI-55

demonstrated with the use of a Rhizobium Nod ${ }^{\top}$ strain, which is unable to synthesize Nod factors and therefore nodulate the plant host.

When a bacterial $\mathrm{Nod}^{-}$mutant strain was genetically modified to secrete cytokinin, trans-zeatin, the induction of uncolonized nodule-like structures on Medicago sativa roots was observed. This demonstrated that cytokinins mimic some of the morphogenetic effects of Nod factors (Cooper and Long, 1994). However, such empty nodules were not able to fix atmospheric nitrogen. Exogenous cytokinins, in a similar way to rhizobia and Nod factors, induced cortical cell divisions, amyloplast deposition and expression of early nodulin genes, including ENOD4O and NIN, in different legume plants (Dehio and de Bruijn, 1992; Jimenez-Zurdo et al., 2000; Mathesius et al., 2000; Murray et al., 2007; Tirichine et al., 2007; Torrey, 1961). Recent data explicitly show that cytokinins are important signals in symbiotic interactions and nodulation, and act downstream of Nod factor perception (Frugier et al., 2008; Gonzalez-Rizzo et al., 2006).

The Nod factor is recognized by receptors containing peptidoglycan-binding lysin (LysM) domains. Downstream of this perception, the other transduction elements have been defined: (i) a leucine-rich repeat receptor-like kinase, (ii) putative cation channels (CASTOR, and POLLUX), (iii) nucleoporins (NUP85 and NUP133) and (iv) the calcium- and calmodulin-dependent kinase (CCaMK, also known as DMI3) (Andriankaja et al., 2007; Middleton et al., 2007; Oldroyd and Downie, 2006; Saito et al., 2007; Schauser et al., 1999), (v) Nod factor signaling pathways 1 and 2 (NSP1, NSP2) and an ethylene response transcription factor (ERN) and (vi) an NIN protein. These are necessary for the regulation of transcription associated with bacterial infection and nodule organogenesis (Fig. 4).

In a similar fashion to snf2, gain-of-function CCaMK alleles also induce the formation of spontaneous nodules in an NSP1-, NSP2- and NIN-dependent manner (Glea- son et al., 2006; Tirichine et al., 2006; Tirichine et al., 2007). These results suggest a linear pathway from Nod factor perception through CCaMK and LHK1 (in Lotus japonicus) or MtCRE1 (in $M$. truncatula) leading to nodule organogenesis. Therefore, rhizobial activation of two cytokinin response regulators, MtRR1 and MtRR4, depends on Nod-factor signal transduction components (Gonzalez-Rizzo et al., 2006). A parallel model, in which two separate signaling pathways converge at NSP2 to mediate nodulation, has also been considered (Oldroyd, 2007). It has been found that ERN transcription factors, which belong to the AP2/ERF family, act together with NSP1 and NSP2 to mediate the transcriptional activation required for the formation of infection threads and nodules (Andriankaja et al., 2007; Middleton et al., 2007). It is possible that cytokinins are involved in the regulation of the expression and nuclear location of ERNs including other transcriptional factors required in nodulation (e.g. NSP2). All experimental data clearly demonstrate the role of cytokinins in effective nodules formation.

\section{Cytokinin receptors in the regulation of nodule organogenesis}

Cytokinin signaling genes are upregulated after rhizobial inoculation. In Medicago truncatula, Sinorhizobium meliloti infection activates a receptor histidine kinase gene, Mtcre1 and subsequently RRs. The latter are similar to the Arabidopsis thaliana cytokinin responsive genes ARR4-5 and ARR10-12 (Gonzalez-Rizzo et al., 2006; Lohar et al., 2006).

Under rhizobial infection, the Mtcre1 gene is expressed in the cortical cells of the Nod factor active zone, followed by development of nodule primordium. Finally, its expression becomes restricted to the nodule meristematic region (Lohar et al., 2006). A decrease in cytokinin accumulation and perception inhibits nodulation. In Lotus japonicus overexpression of heterologous cytokinin, oxidase/dehydrogenase genes, involved in cytokinin degradation, resulted in reduced nodulation (Lohar et al., 2004). Likewise, specific downregulation of Mtcre1 and a loss-of-function mutation in the L. japonicus ortholog, Lhk1 (hit1-1 allele), led to the formation of cytokinin sensitive roots, which dramatically inhibited nodulation (Gonzalez-Rizzo et al., 2006; Murray et al., 2007).

It was also shown that $L$. japonicus gain-of-function mutation in the cytokinin receptor gene, $L H K 1$, induced the spontaneous formation of nodules in the absence of 


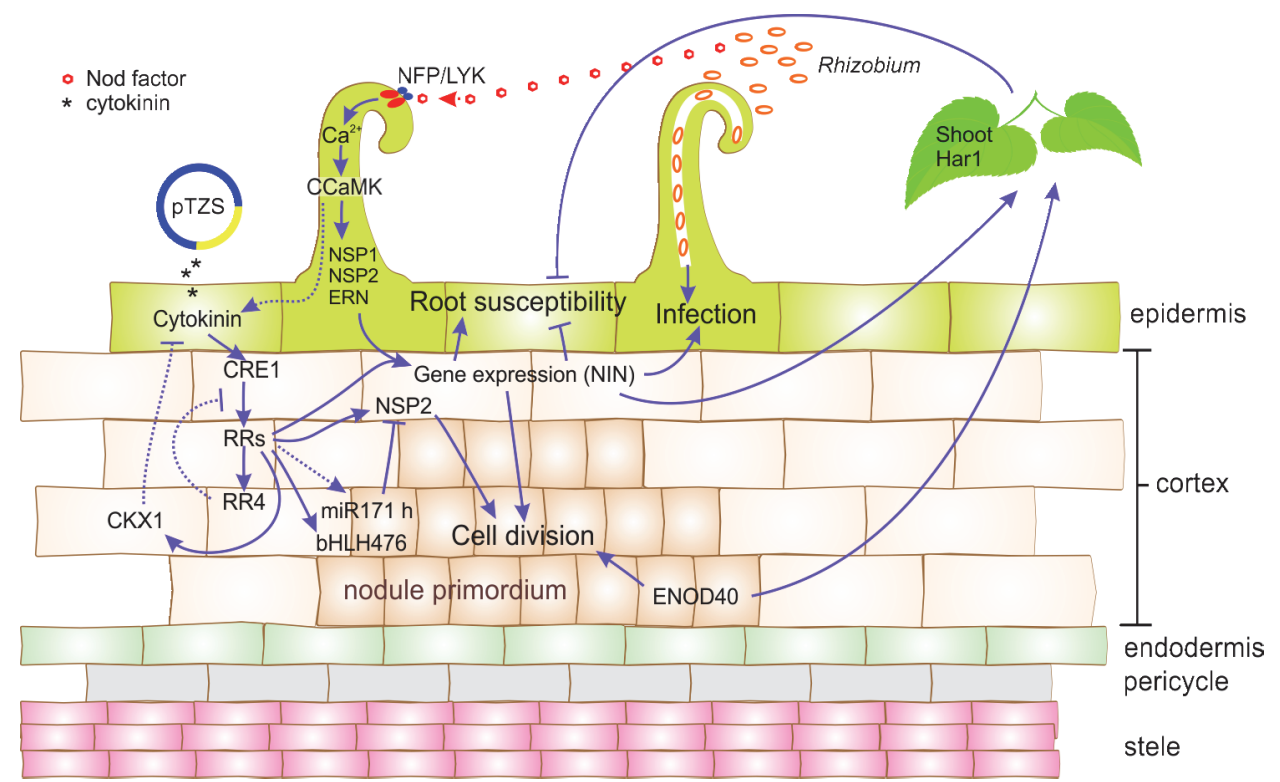

Fig. 4. The role of cytokinin in nodulation. Solid and dotted lines represent proven and putative interactions, respectively. Early nodulation events involve: (i) Nod factor (NF) perception by Nod factor perception/Lys-M kinase receptor (NFP/LYK); (ii) Calcium signaling through a calcium and calmodulin dependent kinase (CCaMK); (iii) activation of Nod factor signaling pathways 1 and 2 (NSP1/2) and ethylene response transcription factor (ERN) and, (iv) nodule inception transcription factor (NIN). Nod factor signaling cascade can be bypassed via cytokinins produced by bacteria (pTZS plasmid) causing NF independent nodulation. In the epidermis NIN is necessary for infection and inhibits root susceptibility to rhizobial signaling. Local and systemic feedback regulation of infection are also cytokinin-dependent. There are also genes that act downstream of the cytokinin pathway: miR171h isoform targeting NSP2 and bHLH476, a direct cytokinin targets, as well as cytokinin oxydase/dehydrogenase (CKX1).

Adapted with modifications from (Ariel et al., 2012; Frugier et al., 2008)

rhizobia. Such mutation is called spontaneous nodule formation 2 (snf2) (Tirichine et al., 2007).

Studies on genes involved in nodule organogenesis directly regulated by cytokinin-induced signals have led to the identification of the 12-bp RR binding site (RRBS). They were found in promoters of several cytokinin-regulated genes linked to nodulation: $R R 4$ (a Type-A Response Regulator) (Plet et al., 2011), and the NSP2 transcription factor (Heckmann et al., 2006; Kalo et al., 2005). The involvement of RRBSs in cytokinin-induced expression of nodulation genes allowed the further search for direct targets of cytokinins functioning in the root cortical cell division and nodule formation. The recently described transcription factor has been named the basic Helix-Loop-Helix (bHLH) TF - bHLH476 (Ariel et al., 2012). Using the RNAi-mediated gene silencing method and an insertional mutagenesis it was also proven that both NSP2 and $b H L H 476$ are direct targets of a cytokinin signaling pathway in the development of an effective symbiosis. This definitely indicates that cytokinin signaling is essential to induce cortical cell divisions and nodule organogenesis.

\section{Cytokinins in the shoot apical meristem}

The activity of cytokinins is essential to maintain undifferentiated, pluripotent cells in a shoot apical meristem (SAM). Werner and co-workers $(2003 ; 2001)$ investigated a transgenic Arabidopsis thaliana overexpressing gene encoding CKXs enzyme. In such plants a decrease in active cytokinins was observed, which subsequently resulted in a sharp reduction in the size of SAM. A similar outcome was obtained from the analysis of the Arabidopsis triple mutant of genes encoding cytokinin receptors ahk2 ahk3 ahk4/cre1. Decreasing cytokinin content resulted in a dramatic reduction in meristem size and leaf-initiation rate. Cytokinins positively affect the shoot apical meristem by upregulating transcription factor STM (SHOOT MERISTEMLESS). They induce cell division and thus prevent their differentiation (Nishimura et al., 2004; Riefler et al., 2006; Rupp et al., 1999; Shani et al., 2006). Although cytokinins play a crucial role in SAM, their level and activity are under very strict control. The central elements in the control of SAM maintenance are KNOTTED1-like homeobox (KNOX1) 
proteins. These transcription factors are repressors of cell differentiation via the establishment of a high cytokinin to gibberellin ratio within SAM cells (Di Giacomo et al., 2008). KNOX1 proteins expression is restricted to SAM, where they suppress the GA20ox gene responsible for gibberellin synthesis (Kyozuka, 2007). Recently, it has been shown that the $S T M$ transcription factor also induces IPT gene expression (Gordon et al., 2009).

Gordon and co-workers also inferred the impact of cytokinins on WUSCHEL (WUS) expression pattern. WUS is a homeodomain transcription factor, which is expressed in the central zone (CZ) cells of the shoot apical meristem. WUS positively regulates stem-cell proliferation by repressing the expression of genes encoding type-A response regulators, such as $A R R 5$ and $A R R 7$. Interactions between type-A $A R R$ genes and cytokinins resemble a negative feedback loop. Exogenously applied cytokinins rapidly elevate the expression level of type-A ARRs which in turn are negative regulators of cytokinin responses by downregulation of WUS expression (Ferreira and Kieber, 2005; Hwang and Sheen, 2001; Sablowski, 2009). Studies on rice have shown that cytokinin content in a shoot apical meristem might be increased thanks to the action of an enzyme with phosphoribohydrolase ( $L O G$ ) activity, which converts inactive cytokinin nucleotides into free base hormones. Rice plant harboring mutation in $L O G$ gene demonstrates a remarkable reduction in SAM size (Kurakawa et al., 2007; Kuroha et al., 2009; Perilli et al., 2010).

\section{Modification of apical dominance}

Apical dominance is a special plant feature which determines its architecture. The main shoot growing in the intact plant is shown to be predominant, simultaneously suppressing the outgrowth of axillary buds. The high content of auxins in the top of the shoot is responsible for this phenomenon. Decapitation of the shoot apex induces cytokinin synthesis, which in turn stimulates shoot branching. Shoot branching and the degree of apical dominance differs between plant species, which is manifested in the large variety of plant shapes. Sato and co-workers (2009) proposed a functional model of an auxin-cytokinin interaction which concerns apical dominance and shoot branching. Auxins derived from the apex induce expression of cytokinin degradation genes $(C K X)$. They also suppress transcription of the IPT gene. At the same time, the auxin efflux carrier (PIN) gene is upregulated, stimulating basipental polar auxin transport in the stem. As a consequence, the outgrowth of axillary buds is repressed. Once the shoot apex is decapitated, a decreasing content of auxin in the stem is observed. This, in turn, activates the IPT gene and de novo synthesis of cytokinins in the stem. Cytokinins follow into the dormant axillary bud and promote their outgrowth. Afterwards, de novo synthesis of auxin (IAA) is initiated and the IPT gene is again repressed (Dun et al., 2006; Foo et al., 2007; Shimizu-Sato et al., 2009).

\section{Cytokinins and root growth}

The root meristem represents a place of continual competition between auxins and cytokinins. The relationship between these hormones reveals a physiological and developmental alteration in the function of a plant organism. It is well known that auxins promote cell division in the $\mathrm{CZ}$ of the root meristem. As a consequence, an increase root size is observed. Cytokinins are also involved in the determination of root size, however they do it in a different manner. They promote cell differentiation in the transition zone (TZ) of the root meristem, which in turn diminishes the overall root size (Dello Ioio et al., 2007; Perilli et al., 2010; Werner et al., 2003; Werner et al., 2001). From the molecular point of view, the path from hormone action to root size is not straightforward. Cytokinin mediation of cell differentiation starts with its signal perception by CRE 1 followed by phosphorylation and dephosphorylation of protein signal transporters. This signal path activates the type-B response regulator ARR1 (Taniguchi et al., 2007). The ARR1 transcription factor acts in trans and initializes the expression of the SHORT HYPOCOTYL2 (SHY2) gene. SHY2 is the auxinresponse repressor gene which belongs to the family of 24 auxin-responsive genes (Aux/IAA) and en-codes a nuclear protein characterized by a very short lifespan (reaching up to $8 \mathrm{~min}$ ) (Tian et al., 2002). It was shown that a loss-of-function mutation in the SHY2 gene results in a larger root meristem size and resistance to cytokinins (Chapman and Estelle, 2009). This gene is expressed in $\mathrm{TZ}$ of the root meristem and negatively regulates the $P I N$ gene and in parallel downregulates expression of cytokinin synthesis genes (IPT). There are eight PIN genes in the Arabidopsis genome. PIN proteins are located asymmetrically on the plasma membrane where they 
direct polar auxin transport within the tissue. Attenuation of PIN proteins activity by cytokinins results in a decreasing rate of auxin in root meristem $\mathrm{CZ}$, leading to the initiation of cell differentiation in $\mathrm{TZ}$ of the root meristem. The growth of the root is finally retarded. Cytokinins alter PIN protein function at the posttranscriptional stage, but the level of PIN transcripts remains unchanged (Zhang et al., 2011). This general signaling model undergoes further control by auxins, which direct degradation of the SHY2 protein and sustention of PIN function, remains auxin transport active. An additional aspect of hormone interactions during the establishment of root meristem size is the cross-talk between cytokinins and ethylene. Cytokinins stimulate ethylene biosynthesis, which itself strongly affects root growth and also induces expression of the PINgene (Ruzicka et al., 2009).

\section{Leaf senescence}

Leaf senescence is a programmed aging process, leading to death. It represents the final stage of leaf development. During this highly regulated genetic process a wide variety of physiological conversions take place, ranging from changes in gene expression and cell metabolism to cell structure. Many biotic and abiotic factors influence leaf senescence (e.g. drought, nutrient limitation, temperature, oxidative stress, pathogen infection). The process accelerates in darkness and slows down in the light (Wingler et al., 1998). Overbalanced catabolic processes can be observed in the cells. Carbon assimilation is replaced by chlorophyll degradation, followed by membrane lipid, protein and nucleic acid decay. During leaf senescence, the cytokinin synthesis gene (IPT) is downregulated, in contrast to cytokinin $C K X_{S}$ genes where the expression level increases (Schippers et al., 2007). Cytokinins delay leaf senescence, inter alia by preventing chlorophyll breakdown. Balibrea Lara and coworkers (2004) showed that cytokinins induce the activity of extracellular invertase, ionically anchored to the cell wall. Subsequently, this enzyme is directly involved in hydrolysis of sucrose to hexose monomers previously released from phloem elements by sucrose transporters. Extracellular invertase, together with the hexose transporter activity, promotes a higher uptake of hexose sugars in senescing leaves. The inhibition of extracellular invertase activity results in the retardation of leaf senescence delay mediated by cytokinins. In the senescing leaf expression of type-A cytokinin signaling genes, ARRs represent a reduced transcription (Buchanan-Wollaston et al., 2005). However, the exogenously applied cytokinin upregulates these response regulators (Rashotte et al., 2003). Moreover, cytokinins induce genes encoding ribosomal proteins (Cerny et al., 2011; Cherepneva et al., 2003; Kimura et al., 2001). Cytokinins inhibit respiration during senescence and prevent oxidation damage in the cell through the control of lipoxygenase and peroxidase expression (downregulation effect), (Boonman et al., 2007; Crowell et al., 1990; Mok and Mok, 2001; Werner et al., 2008).

\section{Regulation of the cell cycle}

Cytokinins were discovered by observation of their ability to stimulate cell division. They promote cytokinesis by participating in cell cycle regulation at both the G1/S phase and G2/M phase progression. Cytokinins increase the amount of the $\mathrm{G} 1$ phase $\mathrm{CycD} 3$ protein (cyclin 3 , type $\mathrm{D}$ ) required for $\mathrm{G} 1 / \mathrm{S}$ transition. Cyclins regulate the substrate specificity of CDK-Cyc (CDK - cycline dependent kinases) complexes (Dewitte et al., 2003; 2007). Type-D cyclins possess an N-terminal $\mathrm{LxCx}(\mathrm{D} / \mathrm{E})$ retinoblastoma-binding motif, responsible for interaction with a retinoblastoma-related protein (RBR). RBR further induces elongation factor $2(\mathrm{E} 2 \mathrm{~F})$, necessary for the promotion of S phase entry (Dewitte et al., 2003; Dewitte et al., 2007; Kim and Park, 2007; Nordström, 2004). The regulatory role of cytokinins in the G2/M transition state is connected with Cyclin dependent serine/threonine kinases (CDK), the main regulatory proteins of the cell cycle. Plants CDKs are divided into seven classes (Doonan and Kitsios, 2009; Vandepoele et al., 2002). CDKs possess a conserved PSTAIRE amino acid sequence located in a non-catalytic domain, which is responsible for binding to a cyclin partner. The CDK/Cyc complex undergoes a post-translational modification of phosphorylation/dephosphorylation. The Cdc25 (cell division cycle 25) factor activates the $\mathrm{CDK} / \mathrm{Cyc}$ complex through dephosphorylation of conserved amino acid residues - Thr 14 and Thr 15. The activity of Cdc25 itself is upregulated by cytokinins (Lipavska et al., 2011).

\section{Cytokinins and pathogen responses}

Plants interact with living organisms either in a symbiotic or antagonistic way. The pathogenic attack is ef- 
fective in the stimulation of the plant immune system. It may be said that "immune reactions are all about hormones talking”. The major conversational partners here are: salicylic acid (SA), jasmonates (JA) and ethylene (ET). However, the more we know about plant defense, the more important cytokinins in these very complex processes become (Jones and Dangl, 2006; Verhage et al., 2010). It is known that some microbial species may synthesize or utilize plant cytokinins during the formation of gall structures. Cytokinin receptors bind both bacterial and plant - derived cytokinins; however, they cause different molecular outputs. After penetration of plant host cells by the below mentioned bacterial species, an abnormal cytokinin synthesis and accumulation occurs, followed by an abnormal cell proliferation. As a consequence, galls form on plant roots (Agrobacterium thumefaciens) or leaves (Rhodococcus fascians). Stimulation of cytokinin receptors results in a higher expression of genes responsible for control of cell division (CycD3). Studies on Arabidopsis thaliana infected by Pseudomonas syringae pv. tomato (Pst; non-cytokinin producing pathogen) demonstrated the involvement of cytokinins in plant defense reactions in a salicylic acid signaling dependent manner (Argueso et al., 2012; Choi et al., 2011; Choi et al., 2010; Hwang et al., 2012). Plantderived cytokinins induce resistance to pathogen infections using a two-component signaling system, which begins with their perception by CRE1/AHK4. In consequence, the type-B response regulator (ARR2) becomes activated. ARR2 binds the salicylic acid response factor (TGA3). TAG3 (TGACG motif-binding protein 3) is involved in the hyperactivation of genes encoding SID proteins (SA biosynthesis) and PR (pathogenesis related) class 1, 2 and 5. PR1 genes are molecular markers of the SA-signaling pathway. The ARR2/TGA3 complex interacts with $p r$ promoters inducing the transcription of $p r$ class 1, 2 and 5 genes. Cytokinins enhance plant immunity by elevation of SA-dependent defense responses. However, SA provides negative feedback in cytokinin signaling as a consequence of their inhibition. In this way a regulatory circle is observed. Surprisingly, tobacco plants infected by Pseudomonas syringae pv. tomato exhibit slightly different defense mechanisms. In this case, cytokinins participate in plant immunity, but do not induce salicylic acid signaling. Grosskinsky and co-workers (2011) discovered that cytokinin synthesis induced by pathogen infection in tobacco does not result in an SA level increase. At the same time, in infected plant cells they observed an accumulation of phytoalexin, such as scopoletin and capsidiol.

Although we have a general insight into the implications of cytokinin in plant defense mechanisms, there is still a great need for further investigation of the plant immune system.

\section{Acknowledgements}

This Project was funded by the Polish Ministry of Science and Higher Education (grants No. N N301 204233 and NN 301 003739) and co-funded by the European Union within the framework of the European Regional Development Fund.

\section{References}

Andriankaja A., Boisson-Dernier A., Frances L., Sauviac L., Jauneau A., Barker D.G., de Carvalho-Niebel F. (2007) AP2-ERF transcription factors mediate Nod factor dependent Mt ENOD11 activation in root hairs via a novel cisregulatory motif. Plant Cell 19(9): 2866-2885.

Argueso C.T., Ferreira F.J., Epple P., To J.P., Hutchison C.E., Schaller G.E., Dangl J.L., Kieber J.J. (2012) Two-component elements mediate interactions between cytokinin and salicylic acid in plant immunity. PLoS Genet. 8(1): 1-7.

Ariel F., Brault-Hernandez M., Laffont C., Huault E., Brault M., Plet J., Moison M., Blanchet S., Ichante J.L., Chabaud M. et al. (2012) Two direct targets of cytokinin signaling regulate symbiotic nodulation in Medicago truncatula. Plant Cell 24(9): 3838-3852.

Armstrong D.J., Burrows W.J., Skoog F., Roy K.L., Soll D. (1969) Cytokinins: distribution in transfer RNA species of Escherichia coli. Proc. Natl. Acad. Sci. USA 63(3): 834841.

Ashikari M., Sakakibara H., Lin S., Yamamoto T., Takashi T., Nishimura A., Angeles E.R., Qian Q., Kitano H., Matsuoka M. (2005) Cytokinin oxidase regulates rice grain production. Science 309(5735): 741-745.

Balibrea Lara M.E., Gonzalez Garcia M.C., Fatima T., Ehness R., Lee T.K., Proels R., Tanner W., Roitsch T. (2004) Extracellular invertase is an essential component of cytokinin-mediated delay of senescence. Plant Cell 16(5): 1276-1287.

Barciszewska M., Keith G., Dirheimer G., Barciszewski J. (1988) The nucleotide sequence of $t R N A(S e r)$ and $t R N A(I l e)$ of yellow lupin seeds. Nucleic Acids Res. 16(16): 8175.

Barciszewski J., Mielcarek M., Stobiecki M., Siboska G., Clark B.F. (2000) Identification of 6-furfuryladenine (kinetin) in human urine. Biochem. Biophys. Res. Commun. 279(1): 69-73.

Bishopp A., Lehesranta S., Vate A., Help H., El-showk S., Scheres B. (2011) Report Phloem-Transported Cytokinin Regulates Polar Auxin Transport and Maintains Vascular Pattern in the Root Meristem. Curr. Biol. 21(11): 927932. 
Boonman A., Prinsen E., Gilmer F., Schurr U., Peeters A. J., Voesenek L. A., Pons T. L. (2007) Cytokinin import rate as a signal for photosynthetic acclimation to canopy light gradients. Plant Physiol. 143(4): 1841-1852.

Buchanan-Wollaston V., Page T., Harrison E., Breeze E., Lim P.O., Nam H.G., Lin J.F., Wu S.H., Swidzinski J., Ishizaki K., et al. (2005) Comparative transcriptome analysis reveals significant differences in gene expression and signalling pathways between developmental and dark/starvation-induced senescence in Arabidopsis. Plant J. 42(4): 567-585.

Caesar K., Thamm A.M., Witthoft J., Elgass K., Huppenberger P., Grefen C., Horak J., Harter K. (2011) Evidence for the localization of the Arabidopsis cytokinin receptors AHK3 and AHK4 in the endoplasmic reticulum. J. Exp. Bot. 62(15): 5571-5580.

Cedzich A., Stransky H., Schulz B., Frommer W. B. (2008) Characterization of cytokinin and adenine transport in Arabidopsis cell cultures. Plant Physiol. 148(4): 1857-1867.

Cerny M., Dycka F., Bobalova J., Brzobohaty B. (2011) Early cytokinin response proteins and phosphoproteins of Arabidopsis thaliana identified by proteome and phosphoproteome profiling. J. Exp. Bot. 62(3): 921-937.

Chapman E.J., Estelle M. (2009) Cytokinin and auxin intersection in root meristems. Genome Biol. 10(2): 1-5.

Cherepneva G.N., Schmidt K.H., Kulaeva O.N., Oemuller R., Kuznetsov V.V. (2003) Expression of the ribosomal proteins S14, S16, L13a and L30 is regulated by cytokinin and abscisic acid: Implication of the involvement of phyto hormones in translational processes. Plant Sci. 165(5): 925-932.

Choi J., Huh S.U., Kojima M., Sakakibara H., Paek K.H., Hwang I. (2010) The cytokinin-activated transcription factor ARR2 promotes plant immunity via TGA3/NPR1dependent salicylic acid signaling in Arabidopsis. Dev. Cell 19(2): 284-295.

Choi J., Choi D., Lee S., Ryu C.M., Hwang I. (2011) Cytokinins and plant immunity: old foes or new friends? Trends Plant Sci. 16(7): 388-394.

Cooper J.B., Long S.R. (1994) Morphogenetic Rescue of Rhizobium meliloti Nodulation Mutants by trans-Zeatin Secretion. Plant Cell 6(2): 215-225.

Crowell D.N., Kadlecek A.T., John M.C., Amasino R.M. (1990) Cytokinin-induced mRNAs in cultured soybean cells. Proc. Natl. Acad. Sci. USA 87(22): 8815-8819.

Czerpak R., Piotrowska A. (2003) Cytokininy, ich struktura, metabolizm iaktywność biologiczna. Kosmos 52:203-215.

de la Serve B.T., Jouanneau J.P., Peaud-Lenoel C. (1984) Incorporation of $N$-Benzyladenine into Messenger Poly $(A)-R N A$ of Tobacco Cells Incubated at Stimulatory or Cytostatic Cytokinin Concentration. Plant Physiol. 74(3): 669-674.

Dehio C., de Bruijn F.J. (1992) The early nodulin gene SrEnod2 from Sesbania rostrata is inducible by cytokinin. Plant J. 2(1): 117-128.

Dello Ioio R., Linhares F.S., Scacchi E., Casamitjana-Martinez E., Heidstra R., Costantino P., Sabatini S. (2007) Cytoki- nins determine Arabidopsis root-meristem size by controlling cell differentiation. Curr. Biol. 17(8): 678-682.

Dewitte W., Riou-khamlichi C., Scofield S., Healy J.M.S., Jacqmard A., Kilby N.J., Murray J.A.H. (2003) Altered Cell Cycle Distribution, Hyperplasia, and Inhibited Differentiation in Arabidopsis Caused by the D-Type Cyclin CYCD3. Plant Cell 15(1): 79-92.

Dewitte W., Scofield S., Alcasabas A.A., Maughan S.C., Menges M., Braun N., Collins C., Nieuwland J., Prinsen E., Sundaresan V., et al. (2007) Arabidopsis CYCD3 D-type cyclins link cell proliferation and endocycles and are ratelimiting for cytokinin responses. Proc. Natl. Acad. Sci. USA 104(36): 14537-14542.

Di Giacomo E., Sestili F., Iannelli M.A., Testone G., Mariotti D., Frugis G. (2008) Characterization of KNOX genes in Medicago truncatula. Plant Mol. Biol. 67(1-2): 135-150.

Doonan J.H., Kitsios G. (2009) Functional evolution of cyclindependent kinases. Mol. Biotechnol. 42(1): 14-29.

Dun E.A., Ferguson B.J., Beveridge C.A. (2006) Apical Dominance and Shoot Branching. Divergent Opinions or Divergent Mechanisms? Plant Physiol. 142(3): 812-819.

Ferreira F.J., Kieber J.J. (2005) Cytokinin signaling. Curr. Opin. Plant Biol. 8(5): 518-525.

Foo E., Morris S.E., Parmenter K., Young N., Wang H., Jones A., Rameau C., Turnbull C.G.N., Beveridge C.A. (2007) Feedback Regulation of Xylem Cytokinin Content Is Conserved in Pea and Arabidopsis. Plant Physiol. 143(3): 1418-1428.

Frebort I., Kowalska M., Hluska T., Frebortova J., Galuszka P. (2011) Evolution of cytokinin biosynthesis and degradation. J. Exp. Bot. 62(8): 2431-2452.

Frugier F., Kosuta S., Murray J. D., Crespi M., Szczyglowski K. (2008) Cytokinin: secret agent of symbiosis. Trends Plant Sci. 13(3): 115-120.

Gillissen B., Bürkle L., André B., Kühn C., Rentsch D., Brandl B., Frommer W.B. (2000) A New Family of High-Affinity Transporters for Adenine, Cytosine, and Purine Derivatives in Arabidopsis. Plant Cell 12(2): 291-300.

Gleason C., Chaudhuri S., Yang T., Munoz A., Poovaiah B.W., Oldroyd G.E. (2006) Nodulation independent of rhizobia induced by a calcium-activated kinase lacking autoinhibition. Nature 441(7097): 1149-1152.

Gonzalez-Rizzo S., Crespi M., Frugier F. (2006) The Medicago truncatula CRE1 cytokinin receptor regulates lateral root development and early symbiotic interaction with Sinorhizobium meliloti. Plant Cell 18(10): 2680-2693.

Gordon S.P., Chickarmane V.S., Ohno C., Meyerowitz E.M. (2009) Multiple feedback loops through cytokinin signaling control stem cell number within the Arabidopsis shoot meristem. Proc. Natl. Acad. Sci. USA: 1-7.

Grosskinsky D.K., Naseem M., Abdelmohsen U.R., Plickert N., Engelke T., Griebel T., Zeier J., Novak O., Strnad M., Pfeifhofer H., et al. (2011) Cytokinins mediate resistance against Pseudomonas syringae in tobacco through increased antimicrobial phytoalexin synthesis independent of salicylic acid signaling. Plant Physiol. 157(2): 815-830. 
Haberer G., Kieber J.J. (2002) Cytokinins. New insights into a classic phytohormone. Plant Physiol. 128(2): 354-362.

Heckmann A.B., Lombardo F., Miwa H., Perry J.A., Bunnewell S., Parniske M., Wang T.L., Downie J.A. (2006) Lotus japonicus nodulation requires two GRAS domain regulators, one of which is functionally conserved in a non-legume. Plant Physiol. 142(4): 1739-1750.

Heyl A., Riefler M., Romanov G.A., Schmulling T. (2012) Properties, functions and evolution of cytokinin receptors. Eur. J. Cell Biol. 91(4): 246-256.

Hirose N., Takei K., Kuroha T., Kamada-nobusada T., Hayashi H. (2008) Regulation of cytokinin biosynthesis, compartmentalization and translocation. J. Exp. Bot. 59(1): 75-83.

Hothorn M., Dabi T., Chory J. (2011) Structural basis for cytokinin recognition by Arabidopsis thaliana histidine kinase 4. Nat. Chem. Biol. 7(11): 766-768.

Hwang I., Sheen J. (2001) Two-component circuitry in Arabidopsis cytokinin signal transduction. Nature 413(6854): 383-389.

Hwang I., Sheen J., Muller B. (2012) Cytokinin signaling networks. Annu. Rev. Plant Biol. 63: 353-380.

Inoue T., Higuchi M., Hashimoto Y., Seki M., Kobayashi M., Kato T., Tabata S., Shinozaki K., Kakimoto T. (2001). Identification of CRE1 as a cytokinin receptor from Arabidopsis. Nature 409(6823): 1060-1063.

Jimenez-Zurdo J.I., Frugier F., Crespi M.D., Kondorosi A. (2000) Expression profiles of 22 novel molecular markers for organogenetic pathways acting in alfalfa nodule development. Mol. Plant Microbe Interact. 13(1): 96-106.

Jones J.D., Dangl J.L. (2006) The plant immune system. Nature 444(7117): 323-329.

Kalo P., Gleason C., Edwards A., Marsh J., Mitra R.M., Hirsch S., Jakab J., Sims S., Long S.R., Rogers J., et al. (2005) Nodulation signaling in legumes requires NSP2, a mem ber of the GRAS family of transcriptional regulators. Science 308(5729): 1786-1789.

Kiba T., Yamada H., Sato S., Kato T., Tabata S., Yamashino T., Mizuno T. (2003) The type-A response regulator, ARR15, acts as a negative regulator in the cytokinin-mediated signal transduction in Arabidopsis thaliana. Plant Cell Physiol. 44(8): 868-874.

Kim Y.-S., Park C.-M. (2007) Membrane Regulation of Cytokinin-Mediated Cell Division in Arabidopsis. Plant Signal. Behav. 2(1): 15-16.

Kimura T., Nakano T., Taki N., Ishikawa M., Asami T., Yoshida S. (2001) Cytokinin-induced gene expression in cultured green cells of Nicotiana tabacum identified by fluorescent differential display. Biosci. Biotechnol. Biochem. 65(6): 1275-1283.

Kudo T., Kiba T., Sakakibara H. (2010) Metabolism and Longdistance Translocation of Cytokinins. J. Integr. Plant Biol. 52: 53-60.

Kurakawa T., Ueda N., Maekawa M., Kobayashi K., Kojima M., Nagato Y., Sakakibara H., Kyozuka J. (2007) Direct control of shoot meristem activity by a cytokinin-activating enzyme. Nature 445(7128): 652-655.
Kuroha T., Tokunaga H., Kojima M., Ueda N., Ishida T., Nagawa S., Fukuda H., Sugimoto K., Sakakibara H. (2009) Functional Analyses of LONELY GUY Cytokinin-Activating Enzymes Reveal the Importance of the Direct Activation Pathway in Arabidopsis. Plant Cell 21(10): 3152-3169.

Kyozuka J. (2007) Control of shoot and root meristem function by cytokinin. Curr. Opin. Plant Biol. 10: 442-446.

Lipavska H., Maskova P., Vojvodova P. (2011) Regulatory dephosphorylation of CDKat $G(2) / M$ in plants: yeast mitotic phosphatase cdc25 induces cytokinin-like effects in transgenic tobacco morphogenesis. Ann. Bot. 107(7): 10711086.

Lohar D.P., Schaff J.E., Laskey J.G., Kieber J.J., Bilyeu K.D., Bird D.M. (2004) Cytokinins play opposite roles in lateral root formation, and nematode and Rhizobial symbioses. Plant J. 38(2): 203-214.

Lohar D.P., Sharopova N., Endre G., Penuela S., Samac D., Town C., Silverstein K.A., VandenBosch K.A. (2006) Transcript analysis of early nodulation events in Medicago truncatula. Plant Physiol. 140(1): 221-234.

Mathesius U., Charon C., Rolfe B.G., Kondorosi A., Crespi M. (2000) Temporal and spatial order of events during the induction of cortical cell divisions in white clover by Rhizobium leguminosarum $b v$. trifolii inoculation or localized cytokinin addition. Mol. Plant Microbe Interact. 13(6): 617-628.

Middleton P.H., Jakab J., Penmetsa R.V., Starker C.G., Doll J., Kalo P., Prabhu R., Marsh J.F., Mitra R.M., Kereszt A., et al. (2007) An ERF transcription factor in Medicago truncatula that is essential for Nod factor signal transduction. Plant Cell 19(4): 1221-1234.

Miyawaki K., Matsumoto-Kitano M., Kakimoto T. (2004) $E_{X-}$ pression of cytokinin biosynthetic isopentenyltransferase genes in Arabidopsis: tissue specificity and regulation by auxin, cytokinin, and nitrate. Plant J. 37: 128-138.

Miyawaki K., Tarkowski P., Matsumoto-Kitano M., Kato T., Sato S., Tarkowska D., Tabata S., Sandberg G., Kakimoto T. (2006) Roles of Arabidopsis ATP/ADP isopentenyltransferases and tRNA isopentenyltransferases in cytokinin biosynthesis. Proc. Natl. Acad. Sci. USA 103(44): 16598-16603.

Mok D.W., Mok M.C. (2001) Cytokinin Metabolism and Action. Annu. Rev. Plant Physiol. Plant Mol. Biol. 52: 89-118.

Murai N., Armstrong D.J., Taller B.J., Skoog F. (1978) Distribution of incorporated, synthetic cytokinins in ribosomal RNA preparations from tobacco callus. Plant Physiol. 61(3): 318-322.

Murray J.D., Karas B.J., Sato S., Tabata S., Amyot L., Szczyglowski K. (2007) A cytokinin perception mutant colonized by Rhizobium in the absence of nodule organogenesis. Science 315(5808): 101-104.

Nishimura C., Ohashi Y., Sato S., Kato T., Tabata S., Ueguchi C. (2004) Histidine Kinase Homologs That Act as Cytokinin Receptors Possess Overlapping Functions in the Regulation of Shoot and Root Growth in Arabidopsis. Plant Cell 16: 1365-1377. 
Nongpiur R., Soni P., Karan R., Singla-Pareek S. L., Pareek A. (2012) Histidine kinases in plants: cross talk between hormone and stress responses. Plant Signal. Behav. 7(10): 1230-1237.

Nordström A. (2004) Cytokinins in Arabidopsis, Tools, Pathways and Interaction with Auxin. Doctoral thesis.

Oka A., Sakai H., Iwakoshi S. (2002) His-Asp phosphorelay signal transduction in higher plants: receptors and response regulators for cytokinin signaling in Arabidopsis thaliana. Genes Genet. Syst. 77(6): 383-391.

Oldroyd G.E., Downie J.A. (2006) Nuclear calcium changes at the core of symbiosis signalling. Curr. Opin. Plant Biol. 9(4): 351-357.

Oldroyd G.E. (2007) Plant science. Nodules and hormones. Science 315(5808): 52-53.

Pas J., von Grotthuss M., Wyrwicz L.S., Rychlewski L., Barciszewski J. (2004) Structure prediction, evolution and ligand interaction of CHASE domain. FEBS Lett. 576(3): 287-290.

Pasternak O., Bujacz G. D., Fujimoto Y., Hashimoto Y., Jelen F., Otlewski J., Sikorski M.M., Jaskolski M. (2006) Crystal structure of Vigna radiata cytokinin-specific binding protein in complex with zeatin. Plant Cell 18(10): 2622-2634.

Perilli S., Moubayidin L., Sabatini S. (2010) The molecular basis of cytokinin function. Curr. Opin. Plant Biol. 13(1): 21-26.

Pieterse C.M., Leon-Reyes A., Van der Ent S., Van Wees S.C. (2009) Networking by small-molecule hormones in plant immunity. Nat. Chem. Biol. 5(5): 308-316.

Plet J., Wasson A., Ariel F., Le Signor C., Baker D., Mathesius U., Crespi M., Frugier F. (2011) MtCRE1-dependent cytokinin signaling integrates bacterial and plant cues to coordinate symbiotic nodule organogenesis in Medicago truncatula. Plant J. 65(4): 622-633.

Punwani J.A., Kieber J.J. (2010) Localization of the Arabidopsis histidine phosphotransfer proteins is independent of cytokinin. Plant Signal. Behav. 5(7): 896-898.

Rashotte A.M., Carson S.D., To J.P., Kieber J.J. (2003) $E_{X-}$ pression profiling of cytokinin action in Arabidopsis. Plant Physiol. 132(4): 1998-2011.

Riefler M., Novak O., Strnad M., Schmu T. (2006) Arabidopsis Cytokinin Receptor Mutants Reveal Functions in Shoot Growth, Leaf Senescence, Seed Size, Germination, Root Development, and Cytokinin Metabolism. Plant Cell 18: 40-54.

Roche P., Debelle F., Maillet F., Lerouge P., Faucher C., Truchet G., Denarie J., Prome J. C. (1991) Molecular basis of symbiotic host specificity in Rhizobium meliloti: nodH and nodPQ genes encode the sulfation of lipo-oligosaccharide signals. Cell 67(6): 1131-1143.

Romanov G.A., Lomin S.N., Schmulling T. (2006) Biochemical characteristics and ligand-binding properties of Arabidopsis cytokinin receptor AHK3 compared to CRE1/AHK4 as revealed by a direct binding assay. J. Exp. Bot. 57(15): 4051-4058.

Rupp H.M., Frank M., Werner T., Strnad M., Schmulling T. (1999) Increased steady state $m R N A$ levels of the STM and KNAT1 homeobox genes in cytokinin overproducing Arabidopsis thaliana indicate a role for cytokinins in the shoot apical meristem. Plant J. 18(5): 557-563.

Ruzicka K., Simaskova M., Duclercq J., Petrasek J., Zazimalova E., Simon S., Friml J., Van Montagu M.C., Benkova E. (2009) Cytokinin regulates root meristem activity via modulation of the polar auxin transport. Proc. Natl. Acad. Sci. USA 106(11): 4284-4289.

Sablowski R. (2009) Cytokinin and WUSCHEL tie the knot around plant stem cells. Proc. Natl. Acad. Sci. USA 106: 16016-16017.

Saito K., Yoshikawa M., Yano K., Miwa H., Uchida H., Asamizu E., Sato S., Tabata S., Imaizumi-Anraku H., Umehara Y., et al. (2007) NUCLEOPORIN85 is required for calcium spiking, fungal and bacterial symbioses, and seed production in Lotus japonicus. Plant Cell 19(2): 610-624.

Sakakibara H. (2006) Cytokinins: Activity, Biosynthesis and Translocation. Annu. Rev. Plant Biol. 57: 431-449.

Schauser L., Roussis A., Stiller J., Stougaard J. (1999) A plant regulator controlling development of symbiotic root nodules. Nature 402(6758): 191-195.

Schippers J.H.M., Jing H.-C., Hille J., Dijkwel P.P. (2007) Developmental and hormonal control of leaf senescence. Annu. Plant Rev. 26: 9-44.

Schmulling T. (2004) Cytokinin. Encyclopedia of Biological Chemistry (Eds. Lennarz, W., Lane, M.D.) Academic Press/Elsevier Science.

Shani E., Yanai O., Ori N. (2006). The role of hormones in shoot apical meristem function. Curr. Opin. Plant Biol. 9(5): 484-489.

Shimizu-Sato S., Tanaka M., Mori H. (2009) Auxin-cytokinin interactions in the control of shoot branching. Plant Mol. Biol. 69(4): 429-435.

Skoog F., Miller C.O. (1957) Chemical regulation of growth and organ formation in plant tissues cultured in vitro. Symp. Soc. Exp. Biol. 11: 118-130.

Skoog F., Armstrong D.J., Cherayil J.D., Hampel A.E., Bock R.M. (1966). Cytokinin activity: localization in transfer RNA preparations. Science 154(3754): 1354-1356.

Spichal L., Werner T., Popa I., Riefler M., Schmulling T., Strnad M. (2009) The purine derivative PI-55 blocks cytokinin action via receptor inhibition. FEBS J. 276(1): 244253.

Suzuki T., Miwa K., Ishikawa K., Yamada H., Aiba H., Mizuno T. (2001) The Arabidopsis sensor His-kinase, AHk4, can respond to cytokinins. Plant Cell Physiol. 42(2): 107-113.

Takei K., Sakakibara H., Sugiyama T. (2001) Identification of Genes Encoding Adenylate Isopentenyltransferase, a Cytokinin Biosynthesis Enzyme, in Arabidopsis thaliana. J. Biol. Chem. 276: 26405-26410.

Takei K., Ueda N., Aoki K., Kuromori T., Hirayama T., Shinozaki K., Yamaya T., Sakakibara H. (2004) AtIPT3 is a Key Determinant of Nitrate-Dependent Cytokinin Biosynthesis in Arabidopsis. Plant Cell Physiol. 45: 1053-1062.

Tanaka Y., Suzuki T., Yamashino T., Mizuno T. (2004) Comparative studies of the AHP histidine-containing phospho- 
transmitters implicated in His-to-Asp phosphorelay in Arabidopsis thaliana. Biosci. Biotechnol. Biochem. 68(2): 462-465.

Taniguchi M., Sasaki N., Tsuge T., Aoyama T., Oka A. (2007) ARR1 Directly Activates Cytokinin Response Genes that Encode Proteins with Diverse Regulatory Functions. Plant Cell Physiol. 48: 263-277.

Tian Q., Uhlir N.J., Reed J.W. (2002) Arabidopsis SHY2 / IAA3 Inhibits Auxin-Regulated Gene Expression. Plant Cell 14: 301-319.

Tirichine L., Imaizumi-Anraku H., Yoshida S., Murakami Y., Madsen L.H., Miwa H., Nakagawa T., Sandal N., Albrektsen A.S., Kawaguchi M., et al. (2006) Deregulation of a Ca2+/calmodulin-dependent kinase leads to spontaneous nodule development. Nature 441(7097): 1153-1156.

Tirichine L., Sandal N., Madsen L.H., Radutoiu S., Albrektsen A.S., Sato S., Asamizu E., Tabata S., Stougaard J. (2007) A gain-of-function mutation in a cytokinin receptor trig gers spontaneous root nodule organogenesis. Science 315(5808): 104-107.

To J.P., Deruere J., Maxwell B.B., Morris V.F., Hutchison C.E., Ferreira F.J., Schaller G.E., Kieber J.J. (2007) Cytokinin regulates type-A Arabidopsis Response Regulator activity and protein stability via two-component phosphorelay. Plant Cell 19(12): 3901-3914.

Torrey J.G. (1961) Kinetin as trigger for mitosis in mature endomitotic plant cells. Exp. Cell Res. 23: 281-299.

Vandepoele K., Raes J., De Veylder L., Rouze P., Rombauts S., Inze D. (2002) Genome-wide analysis of core cell cycle genes in Arabidopsis. Plant Cell 14(4): 903-916.

Verhage A., van Wees S.C., Pieterse C.M. (2010) Plant immunity: it's the hormones talking, but what do they say? Plant Physiol. 154(2): 536-540.
Wang Y.H., Irving H.R. (2011) Developing a model of plant hormone interactions. Plant Signal. Behav. 6(4): 494-500.

Werner T., Motyka V., Strnad M., Schmulling T. (2001) Regulation of plant growth by cytokinin. Proc. Natl. Acad. Sci. USA 98(18): 10487-10492.

Werner T., Motyka V., Laucou V., Smets R., Van Onckelen H., Schmulling T. (2003) Cytokinin-deficient transgenic Arabidopsis plants show multiple developmental alterations indicating opposite functions of cytokinins in the regulation of shoot and root meristem activity. Plant Cell 15(11): 2532-2550.

Werner T., Holst K., Pors Y., Guivarc'h A., Mustroph A., Chriqui D., Grimm B., Schmulling T. (2008) Cytokinin deficiency causes distinct changes of sink and source parameters in tobacco shoots and roots. J. Exp. Bot. 59(10): 2659-2672.

Wingler A., Schaewen A.V., Leegood R.C., Lea P.J., Quick W.P. (1998) Regulation of Leaf Senescence by Cytokinin, Sugars, and Light Effects on NADH-Dependent Hydroxypyruvate Reductase. Plant Physiol. 116: 329-335.

Wulfetange K., Lomin S.N., Romanov G.A., Stolz A., Heyl A., Schmulling T. (2011) The cytokinin receptors of Arabidopsis are located mainly to the endoplasmic reticulum. Plant Physiol. 156(4): 1808-1818.

Zhang W., To J.P., Cheng C.Y., Eric Schaller G., Kieber J.J. (2011) Type-A response regulators are required for proper root apical meristem function through post-transcriptional regulation of PIN auxin efflux carriers. Plant J. 68(1): 1-10.

http:// dx. doi. org/ 10. 1105/ tpc. 110. tt0310 